\title{
Non-polio enteroviruses among healthy children in the Philippines
}

\author{
Maria Melissa Ann Jiao' ${ }^{1}$, Lea Necitas Apostol' ${ }^{1}$, Maricel de Quiroz-Castro², Youngmee Jee ${ }^{3}$, Vito Roque Jr ${ }^{4}$, \\ Manuel Mapue $I^{5}$, Frances Marsha Navarro ${ }^{6}$, Cleo Fe Tabada ${ }^{7}$ and Amado Tandoc $\| I^{1^{*}}$ (i)
}

\begin{abstract}
Background: Enteroviruses (EVs) are most commonly associated with either mild or asymptomatic infections, however, the presence of silent carriers in the community has been proven to play a crucial role in the spread of diseases such as hand, foot, and mouth disease (HFMD) that records high incidence in Asia Pacific region. In the Philippines, limited information is available on the etiology and prevalence of enterovirus outside the Acute Flaccid Paralysis (AFP) surveillance, thus, a study to determine the baseline prevalence of Non-Polio Enteroviruses (NPEVs) among healthy Filipino children was conducted.

Methods: A descriptive, cross-sectional study was performed to determine the prevalence of NPEV among healthy children under 6 years old in the Philippines. Duplicate stool samples were collected from 360 healthy children residing in three major urban cities in the country. Virus isolation and polymerase chain reaction were performed to identify enteroviruses present in the samples. To determine if the results of the study are comparable to the AFP surveillance data, the results of the study were compared to the prevalence and isolation rate among AFP cases of the similar cases collected the same year.
\end{abstract}

Results: Prevalence of enteroviruses among healthy children was found to be at $24.7 \%$. Comparing the NPEV rates from the study and AFP surveillance of similar age and the same year of collection, there was no significant difference in NPEV case prevalence. The study identified a total of 19 different enterovirus serotypes with majority belonging to species Enterovirus B (EV-B).

Conclusion: The study was able to establish a baseline NPEV case prevalence of $24.7 \%$ among healthy children aged under 6 years old in three major urban sites in the Philippines. The high isolation of NPEV among healthy children signifies continuous fecal-oral transmission of enteroviruses in the community.

Keywords: Acute flaccid paralysis, Laboratory, Sequencing, Virus isolation, Coxsackievirus, Hand, Foot and mouth disease

\section{Background}

Enteroviruses (EVs) of the Picornaviridae family are clustered into 15 species, of which, four are isolated exclusively in humans (EV- A to EV D) [1, 2]. EV infections are most commonly associated with either mild or asymptomatic infections. As an example, poliovirus, despite being highly contagious, has ratios of asymptomatic to paralytic cases that ranges from 50:1 to 1000:1 [3]. However, EVs are also associated with outbreaks of more serious diseases, such as hand, foot, and mouth disease (HFMD) and aseptic meningitis which results in considerable morbidity

\footnotetext{
* Correspondence: amado.tandocMD@gmail.com

'National Polio Laboratory, Department of Virology, Research Institute for

Tropical Medicine, Muntinlupa City, Philippines

Full list of author information is available at the end of the article
}

and mortality [4]. They are spread mainly through fecaloral route with highest risk among children due to poor hygiene and low immunity levels.

It has been proven that asymptomatic carriers excreting EVs play a crucial role in the spread of poliovirus [5] and HFMD and their silent presences help perpetuate EV circulation in their community [6]. Evidence also suggests association between EV subtypes, particularly, Coxsackievirus B virus and chronic illnesses.

In the Philippines, the only information available about the epidemiology of EVs in the country is limited to cases reported under the Acute Flaccid Paralysis (AFP) surveillance [7]. The main importance of the isolation of EVs in AFP cases has been limited to its usefulness in

(c) The Author(s). 2020 Open Access This article is distributed under the terms of the Creative Commons Attribution 4.0 International License (http://creativecommons.org/licenses/by/4.0/), which permits unrestricted use, distribution, and reproduction in any medium, provided you give appropriate credit to the original author(s) and the source, provide a link to the Creative Commons license, and indicate if changes were made. The Creative Commons Public Domain Dedication waiver (http://creativecommons.org/publicdomain/zero/1.0/) applies to the data made available in this article, unless otherwise stated. 
assessing proper handling and transportation of AFP stool samples [8].

This study conducted in 2015 aimed to establish a baseline prevalence of non-polio enteroviruses (NPEVs) among healthy children under 6 years old in three selected sites in the Philippines and to identify the serotypes of the circulating EV in the community. The information gathered from this study will augment the information available on NPEVs in the country outside of what is captured by the AFP surveillance.

\section{Methods}

\section{Study design}

A descriptive, cross-sectional study was designed to determine the prevalence of NPEV among healthy children under 6 years old in three major urban cities in the Philippines (Fig. 1). The study was conducted in urban areas in three different regions: (1) National Capital Region (NCR) in Barangay Addition Hills, Mandaluyong, Metro Manila; (2) Region VII in Barangay Carreta, Cebu City; and (3) Region XI in Barangay Buhangin, Davao City, Davao Philippines.

These sites were purposively selected as they were near the Department of Health-Regional Offices and had a barangay health center with sufficient cold storage equipment to store the collected stool samples. The minimum sample size computed for this study was 292 . This was based on a $10.6 \%$ NPEV prevalence from a similar study conducted in China [9], 95\% level of confidence, $5 \%$ precision estimate, design effect of 2 . Additional 68 children were added to compensate for possible non-response, thus, a total of 360 healthy children (120 per site) under 6 years old were randomly selected from a sampling frame gathered through a survey of the health workers in their assignment areas. Only one child per household was permitted to join the study and the current health status of the participants was established to allow only healthy children to participate. "Healthy child" was defined as a child who, by clinical history and physical examination, did not present with symptoms that may be associated with enteroviral infections such as AFP, diarrhea, fever, cough, colds, conjunctivitis, and HFMD.

The study protocol was submitted to and approved by the Research Institute for Tropical Medicine (RITM)- Institutional Review Board and was conducted in compliance with the principles of the Declaration of Helsinki. Since the study participants are children under 6 years old, written informed consent was sought from the children's parent or legal guardian. After the completion of viral testing, parents and guardians were informed of their ward's results and those found to be positive for enteroviruses were advised to visit their health center physician for proper clinical management.

\section{Study procedures}

\section{Stool survey}

The stool survey was performed between February and May 2015. Standard physical examination and clinical history were taken by study physicians to assess the child's health status. Signs and symptoms that may indicate current enteroviral infection, such as AFP, gastroenteritis, influenza-like illness, encephalitis, myocarditis, HFMD, and conjunctivitis were evaluated. If the child was found healthy, the parents or guardians were instructed to collect two stool samples from their child, at least $24 \mathrm{~h}$ apart. Two stool samples were required to compensate for the intermittent shedding of the virus $[10,11]$. To ensure that cold chain is maintained, parents and guardians were provided appropriate sample containers, ice pack, and a detailed instruction on proper sample collection. After collection, they were advised to forward samples to the barangay health center. From there, the samples were shipped by the Regional Epidemiology and Surveillance Unit staff to the National Reference Laboratory (NRL) for Polio and other Enteroviruses-RITM for testing.

\section{Virus isolation}

Stool samples were labeled with the study identification numbers prior to sample processing and testing. Virus isolation was performed at the NRL for Polio and other EnterovirusesRITM, following the WHO standard procedures for poliovirus isolation. Briefly, all stool samples were treated with chloroform and antibiotics, then, $200 \mu \mathrm{L}$ of the stool extracts was inoculated into two rhabdomyosarcoma (RD-A) and two L20B cell lines. EVs are very diverse; thus, no single cell line is susceptible to all EV species. L20B is specific for polioviruses while RD-A can grow most EV species. These tubes were observed for a total of 10-14 days and the infected tissue culture fluids (ITCF) of tubes showing the characteristic cytopathic effect (CPE) of enterovirus (rounding necrosis) were harvested and stored for subsequent testing [8]. Negative cell control tubes were also observed together with the samples and these were used to compare the appearance of the normal, healthy cells and the infected ones.

\section{Sequencing}

EV-positive ITCFs were selected and sent to the National Institute for Health- Korea Center for Disease Control and Prevention (NIH-KCDC) for partial VP1 gene sequencing according to the institute's protocol. VP1 was targeted since it is the best region for phylogeny-based classification. If case both stool samples of the child yielded NPEVs, only the first stool isolate was included for sequencing.

In brief, viral ribonucleic acid (RNA) was extracted using Tecan Freedom Evo $^{\mathrm{Tm}}$ (Tecan Group Ltd., Männedorf, Switzerland). Enterovirus gene was amplified through 


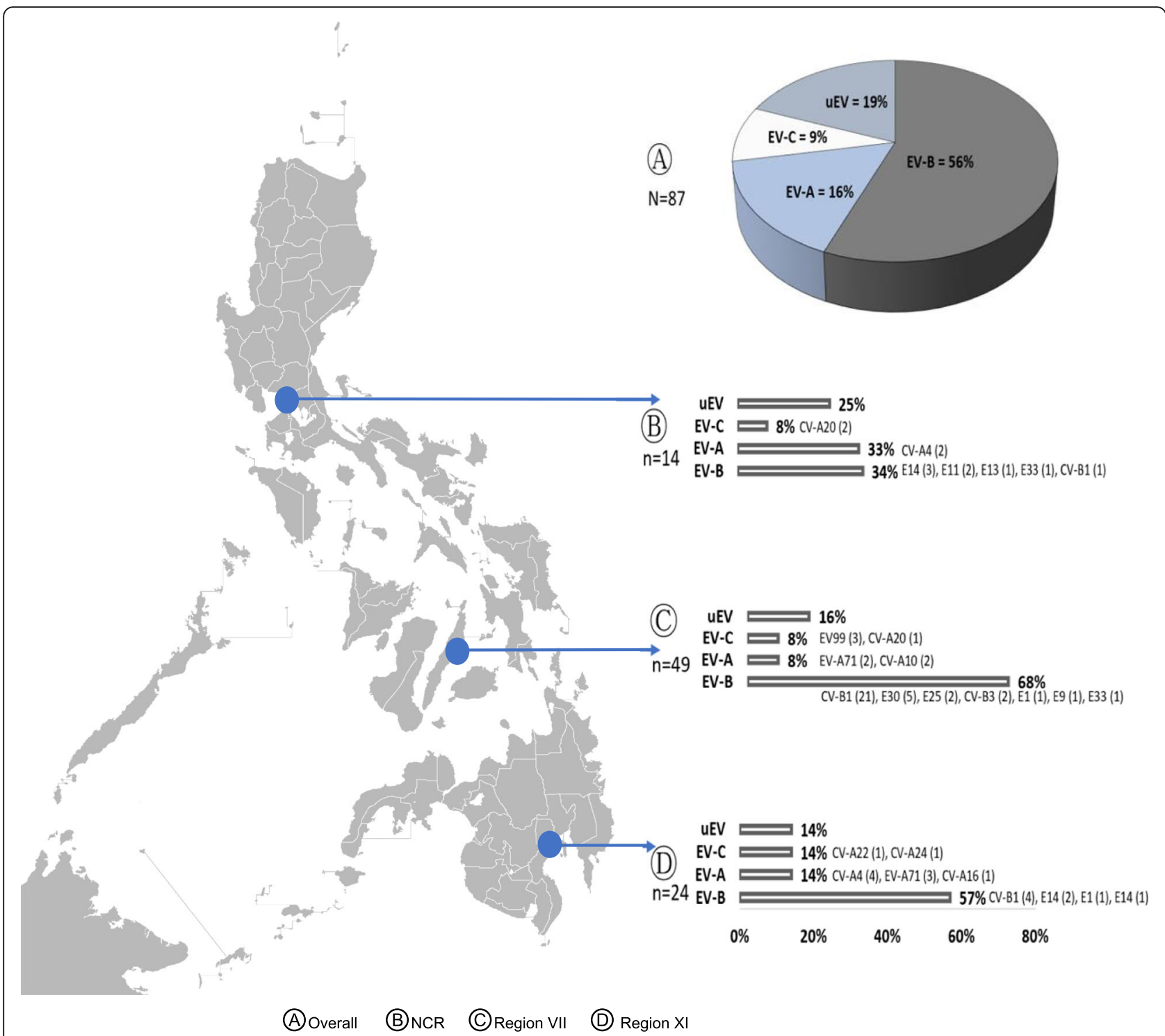

Fig. 1 NPEV isolates among healthy children, Philippines, 2015. uEV (untyped EV) - CPE (+) samples on RD-A cell line and RNA detected in PCR but (-) in sequencing Image of Philippine map taken from https://commons.wikimedia.org/wiki/File:BlankMap-Philippines.png

polymerase chain reaction (PCR) using iNtRON iNNOPLEX ${ }^{\mathrm{m}}$ Enterovirus VP1 detection kit (Bulldog Bio, Inc., Portsmouth, New Hampshire). Amplified products were then sent to Macrogen Korea and to Cosmogenetech Korea for Sanger sequencing. Sequencing results were cleaned and aligned using DNA Star ${ }^{\text {Tix }}$ software (DNASTAR, Inc., Madison, Wisconsin) and MEGA software v.7 A BLAST search was then conducted to identify the enterovirus serotype [12]. Sequences generated from the study were submitted to GenBank with accession numbers: MK959771 to MK959836 and MK977636 to MK977640.

\section{Statistical analysis}

All questionnaires and signed informed consent forms were checked in the field for completeness. Data entry was performed using Epi Info v. 3.5 .3 (Centers for Disease Control and Prevention, Atlanta, Georgia). Comparison of sex, age group and location with the NPEV prevalence as well as comparison in between groups was analyzed by using Chi-square test, and $p$ values $<0.05$ were considered statistically significant. The data gathered from the study were also compared to AFP surveillance cases under 6 years old.

\section{Results}

Prevalence of NPEV

The mean age of the participants is 2.4 and an almost equal proportion of males and females, 51 and 49\%, respectively. 
Two stool samples were collected from each participant. Of the 720 total collected stool samples from 360 children, NPEVs were isolated in 129 (17.9\%) samples from 89 cases. Of these 129 samples, 126 were single isolates of EVs while three were mixed with poliovirus type 3, Sabinlike strain. NPEVs were isolated in 89 children $(89 / 360)$ or $24.7 \%$ of participants. Among these positive participants, $50.6 \%(45 / 89)$ are females and $60.7 \%$ (54/89) belong to the 1 to 3 years old age group. Among the three study sites, Region VII had the highest detected case prevalence with 51 out of the 120 study participants $(42.5 \%)$ yielded at least 1 NPEV from their stool samples. NPEV case prevalence was different among the study sites $\left(\chi^{2}=32.81, p\right.$ value $=<0.001, \mathrm{df}=2)$. Likewise, the NPEV case prevalence in Region VII was highest followed by NCR and Region XI, respectively. Analysis showed also that there was no significant difference in NPEV case prevalence among males and females and also between age groups in the study (Table 1).

Comparative analysis on the NPEV case prevalence and isolation rate (Table 2) reported by the study with those reported AFP cases under 6 years old in 2015 was also done. There was no significant difference in both NPEV case prevalence and NPEV isolation rate except for Region $\mathrm{XI}$ where there was a difference in terms of NPEV isolation rate among cases ( $p$-value 0.046) (Table 2).

\section{Molecular sequencing result}

The study identified a total of 19 different enterovirus serotypes with majority belonging to species EV-B with 11 different serotypes detected. The predominant circulation pattern of the EV-B species was seen in all sites NCR at 57\%, Region VII at $63 \%$ and Region XI at $34 \%$. No subtype or serotype under EV-D was detected. Isolation from EV-A (16\%) was higher than EV-C (9\%). Coxsackievirus B1 (CV-B1) is the most common as it comprised $29.9 \%$ of the NPEVs identified. In this study,

Table 1 Demographic information of participants during 2015

\begin{tabular}{|c|c|c|c|c|c|c|}
\hline \multirow[t]{2}{*}{ Characteristics } & \multicolumn{2}{|c|}{ NPEV Positive } & \multicolumn{2}{|c|}{ NPEV Negative } & \multirow{2}{*}{$\begin{array}{l}x^{2} \\
\text { test }\end{array}$} & \multirow{2}{*}{$\begin{array}{l}p- \\
\text { value }\end{array}$} \\
\hline & No. & $\%$ & No. & $\%$ & & \\
\hline \multicolumn{7}{|l|}{ Sex } \\
\hline Males & 44 & 23.78 & 141 & 76.22 & 0.09 & 0.763 \\
\hline Females & 45 & 25.71 & 130 & 74.29 & & \\
\hline \multicolumn{7}{|l|}{ Age Group } \\
\hline$<1$ year & 13 & 21.67 & 47 & 78.33 & 3.71 & 0.156 \\
\hline $1-3$ years & 54 & 28.88 & 133 & 71.12 & & \\
\hline 4-5 years & 22 & 19.47 & 91 & 80.53 & & \\
\hline \multicolumn{7}{|c|}{ Geographic Location } \\
\hline NCR & 24 & 20.00 & 96 & 80.00 & 32.81 & $<0.001$ \\
\hline Region VII & 51 & 42.50 & 69 & 57.50 & & \\
\hline Region XI & 14 & 11.67 & 106 & 88.33 & & \\
\hline
\end{tabular}

due to the limitation of the method used, only $81 \%$ of the NPEVs isolated were characterized. The remaining $19 \%$ of NPEVs did not produce clean sequences and thus, were termed as untypable EVs (uEVs).

\section{Discussion}

The study aims to determine the baseline NPEV rate among healthy Filipino children under 6 years old. In this study, the prevalence among participants is $24.7 \%$, as NPEVs were isolated in the stool sample of 89 out of 360 enrolled participants. In contrast with the studies done in Indonesia and South-Western India [13, 14], the notion that males are more likely to contract EV infection was not established in this study. The study revealed that NPEV case prevalence among these age brackets $(<1,1-3$ and 4-5) were almost equal indicating that the chances of NPEV infection among these age groups, from infancy to preschool age, is comparable.

The study was able to establish the predominant circulation EV-B species, particularly, CV-B1 which accounted for around $30 \%$ of all EV species isolated. The isolation of CV-B1 in all sites is consistent with a previous study where Coxsackievirus B (CVB) was classified as one of the EV serotypes with endemic circulation in the Philippines [15]. This EV species has been known to be the most common viral cause of human heart infections [16]. There was also an isolation of CV-B4 from a child enrolled in the study and this subtype is known to be an environmental risk factor in the non-genetic causes of type 1 diabetes mellitus [17].

Previous study on the characterization of enterovirus isolates from AFP cases in the Philippines showed that the circulating isolates are, in decreasing order, EV-B, followed by EV-C then by EV-A species [7]. This circulation pattern is also seen in other studies from Asian countries $[18,19]$. This pattern was in contrast with the results of this study wherein a minor difference in the proportion was seen for EV-A and EV-C species. While all sites followed the isolation pattern of EV-B $>\mathrm{EV}-\mathrm{A}>$ $\mathrm{EV}-\mathrm{C}$, there is a variation in the proportion of species detected per region especially in NCR where EV-A has almost the same as EV-B isolation. All of the detected EV serotypes among healthy children mirror the EV serotypes isolated from AFP cases and environmental samples in previous reports except for the detection of CV-A22. The detection of CV-A22 in the Philippines was first identified and documented in this study $[7,20]$.

The study was also able to detect EV-A71 and CVA16 in healthy children and this finding is significant as these are usually associated with HFMD [21-23]. This finding, however, is not exclusive to this study, as a similar result was seen in the survey of healthy children conducted in Shenzhen and Yunnan Province, China. The isolation of these pathogens among 
Table 2 Comparison of NPEV case prevalence and isolation rate among healthy children and AFP cases under 6 old, 2015

\begin{tabular}{|c|c|c|c|c|c|c|c|c|c|c|c|c|c|}
\hline \multirow[t]{2}{*}{ Isolation } & \multicolumn{2}{|c|}{ NPEV Positive } & \multicolumn{2}{|c|}{ NPEV Negative } & \multirow{2}{*}{$\begin{array}{l}x^{2} \\
\text { test }\end{array}$} & \multirow{2}{*}{$\begin{array}{l}p- \\
\text { value }\end{array}$} & \multirow[t]{2}{*}{ Case } & \multicolumn{2}{|c|}{ NPEV Positive } & \multicolumn{2}{|c|}{ NPEV Negative } & \multirow{2}{*}{$\begin{array}{l}x^{2} \\
\text { test }\end{array}$} & \multirow{2}{*}{$\begin{array}{l}p- \\
\text { value }\end{array}$} \\
\hline & No. & $\%$ & No. & $\%$ & & & & No. & $\%$ & No. & $\%$ & & \\
\hline \multicolumn{14}{|l|}{ NCR } \\
\hline $\mathrm{HC}$ & 20 & 8.3 & 220 & 91.7 & & *0.59 & $\mathrm{HC}$ & 14 & 11.7 & 106 & 88.3 & & ${ }^{*} 0.40$ \\
\hline AFP $<6$ & 4 & 7.8 & 47 & 92.2 & & & AFP $<6$ & 2 & 7.4 & 25 & 92.6 & & \\
\hline \multicolumn{14}{|c|}{ Region VII } \\
\hline $\mathrm{HC}$ & 77 & 32.1 & 163 & 67.9 & & 0.010 & & 51 & 42.5 & 69 & 57.5 & & ${ }^{*} 0.38$ \\
\hline AFP $<6$ & 2 & 14.3 & 12 & 85.7 & & & AFP $<6$ & 2 & 28.6 & 5 & 71.4 & & \\
\hline \multicolumn{14}{|l|}{ Region XI } \\
\hline $\mathrm{HC}$ & 32 & 13.3 & 208 & 86.7 & 3.97 & 0.84 & & 24 & 20.0 & 96 & 80.0 & & ${ }^{*} 0.20$ \\
\hline AFP $<6$ & 10 & 25.6 & 29 & 74.4 & & & AFP $<6$ & 6 & 31.6 & 13 & 68.4 & & \\
\hline \multicolumn{14}{|c|}{ All sites/ Philippines } \\
\hline $\begin{array}{l}\mathrm{HC} \\
\text { AFP }<6\end{array}$ & $\begin{array}{l}129 \\
51\end{array}$ & $\begin{array}{l}17.9 \\
16.9\end{array}$ & $\begin{array}{l}591 \\
251\end{array}$ & $\begin{array}{l}82.1 \\
83.1\end{array}$ & 0.16 & $<0.001$ & $\begin{array}{l}\mathrm{HC} \\
\text { AFP }<6\end{array}$ & $\begin{array}{l}89 \\
32\end{array}$ & $\begin{array}{l}24.7 \\
20.8\end{array}$ & $\begin{array}{l}271 \\
122\end{array}$ & $\begin{array}{l}75.3 \\
79.2\end{array}$ & 0.93 & 0.334 \\
\hline
\end{tabular}

*Fisher exact test $p$-value

healthy population is considered an important factor in the continuous circulation of the disease in the community [6,9]. These EV types were also detected in previous studies on NPEVs among AFP cases and environmental samples in the Philippines, which may be suggestive of indigenous circulation of these pathogens in the country [7,20]. Further analysis indicated that the EV-A71 in this study belonged to genogroup $\mathrm{C}$, specifically the $\mathrm{C} 2$ cluster which is genetically homologous to the EV-A71 C2 cluster reported among AFP cases [15]. While neighboring countries in the Asia Pacific region revealed high mortality rates caused by EV-A71 of the genogroup C such as in China, [24] the Philippines has yet to report any fatal case. Data from a comprehensive and longitudinal HFMD study on the overall EV-A71 epidemiology is crucial to conclude that $\mathrm{C} 2$ cluster of EVA71 found in the Philippines is only causing mild disease or even asymptomatic infection.

The age range of all AFP cases is children under 15 years old, therefore, the study decided to compare the results of the study from AFP cases of the same age because a study conducted in Sweden from 2003 to 2007 has shown that the peak of EV isolation is among 18 month-old participants [25] and several other studies suggest that enteroviral infection is greater among younger children [13, 26, 27]. The fact that the study participants' ages (0-5 years old) do not match those of the AFP surveillance cases (0-15 years old) might be a factor for the difference in NPEV case prevalence and isolation rate.

\section{Conclusion}

The study was able to establish a baseline NPEV case prevalence of $24.7 \%$ among healthy children aged under 6 years old in three major urban sites in the Philippines.
The high isolation of NPEV among healthy children signifies continuous fecal-oral transmission. The study was also able to determine EV-B as the most prevalent species of EV in the country.

\section{Limitation of the study}

The study accepts the limitation brought about by using only two cell lines to detect EVs. Several studies conducted showed that the best cell line to use is the MRC5 cells as it yields the best result [28, 29]. The laboratory elected to use the RD-A and L20B cell lines and follow the WHO protocol for poliovirus identification. Despite this, the study was able to isolate CV-A22. CV-A22 was first isolated from a healthy person from Chulman, Russia [30] and this type is rarely seen because of its difficulty to be isolated through tissue culture techniques [31]. In this study, the isolate came from a 3 years old child from Region XI.

The molecular method used in the study limited the detection of EVs as uEVs accounts for 19\% of the overall EV isolation. The gene targeted by the assay is the VP1 region since it is the best region for phylogeny based classification $[32,33]$. For a more comprehensive picture on diversity of EVs among healthy children, a more sensitive method that could identify all possible EV serotypes should be used for subsequent studies. Nonetheless, the method was able to detect newer EVs like Enterovirus C99 (EV-C99).

\footnotetext{
Acknowledgements

The authors are thankful for the technical support of the members of the National Polio Laboratory, Ms. Mary Lorraine Mationg and Mr. Alvin G. Tan for their assistance in data analysis, Department of Health Epidemiology Bureau, Family Health Office, and the Regional Epidemiology Surveillance Unit from NCR, Regions VII and XI, together with the Rural Health Unit staff of Brgy. Addition Hills, Mandaluyong, Brgy. Carreta, Cebu City and Brgy. Buhangin, Davao City.
} 


\section{Authors' contributions}

$M J, A T, M C, Y J, V R, M M, F N$ and $C T$ formulated the goals and developed the framework of the research study. MJ, AT and LA coordinated and supervised study site activities. MJ performed laboratory work and data cleaning and, together with $L A$, analyzed data and drafted the paper. All authors read and approved the final manuscript.

\section{Funding}

This study was funded by the World Health Organization (WHO) Philippines. The Division for Vaccine Research, National Institute for Health, Korea Centers for Disease Control and Prevention facilitated enteroviral sequencing and analysis (Funding number: 4845-300).

\section{Availability of data and materials}

The datasets generated and analyzed during the study are not publicly available for the data privacy protection of participants but are available from the corresponding author on reasonable request.

The partial VP1 sequences of the enterovirus were deposited in GenBank under accession numbers: MK959771 to MK959836 and MK977636 to MK977640.

\section{Ethics approval and consent to participate}

The study was approved by Research Institute for Tropical Medicine-Institutional Review Board on December 9, 2014 (RITM IRB 2013-038). A written informed consent in a language understood by the parents/guardians was given and explained to them. A completed and signed informed consent form from each participant was required prior to their inclusion to the study.

\section{Consent for publication}

Not applicable.

\section{Competing interests}

The authors declare that they have no competing interests.

\section{Author details}

${ }^{1}$ National Polio Laboratory, Department of Virology, Research Institute for Tropical Medicine, Muntinlupa City, Philippines. ${ }^{2}$ World Health Organization Country Office, Manila, Philippines. ${ }^{3}$ Center for Infectious Disease Research, National Institute of Health, Korea Center for Disease Control and Prevention, Cheongju, Chungcheongbuk-do, South Korea. ${ }^{4}$ Department of Health-Epidemiology Bureau, Manila, Philippines. ${ }^{5}$ Department of Health-Center for Health Development NCR, Mandaluyong City, Philippines. ${ }^{6}$ Department of Health-Center for Health Development Region VII, Cebu City, Philippines. ${ }^{7}$ Department of Health-Center for Health Development Region XI, Davao City, Philippines.

Received: 15 August 2019 Accepted: 27 January 2020

Published online: 03 February 2020

\section{References}

1. Zell R, Delwart E, Gorbalenya AE, Hovi T, King AMQ, Knowles NJ, Lindberg AM, Pallansch MA, Palmenberg AC, Reuter G, et al. ICTV virus taxonomy profile: Picornaviridae. J Gen Virol. 2017;98(10):2421-2.

2. Knipe DHP. Fields Virology. 5th ed. Philadelphia: Lippincott Williams \& Wilkins; 2007. p. 847

3. Mehndiratta MM, Mehndiratta P, Pande R. Poliomyelitis: historical facts, epidemiology, and current challenges in eradication. Neurohospitalist. 2014; 4(4):223-9.

4. Organization WH: Enterovirus Surveillance Guidelines: Guidelines for enterovirus surveillance in support of the Polio Eradication Initiative. 2015.

5. Mach O, Verma H, Khandait DW, Sutter RW, O'Connor PM, Pallansch MA, Cochi SL, Linkins RW, Chu SY, Wolff C, et al. Prevalence of asymptomatic poliovirus infection in older children and adults in northern India: analysis of contact and enhanced community surveillance, 2009. J Infect Dis. 2014; 210(Suppl 1):S252-8.

6. Wu Q, Fu X, Jiang L, Yang R, Cun J, Zhou X, Zhou Y, Xiang Y, Gu W, Fan J, et al. Prevalence of enteroviruses in healthy populations and excretion of pathogens in patients with hand, foot, and mouth disease in a highly endemic area of Southwest China. PLoS One. 2017;12(7):e0181234.

7. Apostol LN, Suzuki A, Bautista A, Galang H, Paladin FJ, Fuji N, Lupisan S, Olveda R, Oshitani $\mathrm{H}$. Detection of non-polio enteroviruses from 17 years of virological surveillance of acute flaccid paralysis in the Philippines. J Med Virol. 2012;84(4):624-31.

8. Organization WH, editor. Polio Laboratory Manual. 4th ed. In: Polio Laboratory Manual 4th Edition. Edited by Organization WH; 2010.

9. Wu W, Xu WB, Chen L, Chen HL, Liu Q, Wang DL, Chen YJ, Yao W, Li G, Feng $B$, et al. Molecular identification and analysis of human enteroviruses isolated from healthy children in Shenzhen, China from 2010 to 2011. PLoS One. 2013;8(6):e64889.

10. Pallansch M, Roos R. Enteroviruses: Polioviruses, coxsackieviruses, echoviruses, and newer enteroviruses. In: Knipe D, Howley P, editors. Fields Virology, vol. 1. 5th ed. Philadelphia: Lippincott Williams and Wilkins; 2007. p. 840-84.

11. Tangermann RH, Lamoureux C, Tallis G, Goel A. The critical role of acute flaccid paralysis surveillance in the global polio eradication initiative. Int Health. 2017;9(3):156-63.

12. Altschul SF, Gish W, Miller W, Myers EW, Lipman DJ. Basic local alignment search tool. J Mol Biol. 1990;215(3):403-10.

13. Laxmivandana R, Yergolkar P, Gopalkrishna V, Chitambar SD. Characterization of the non-polio enterovirus infections associated with acute flaccid paralysis in South-Western India. PLoS One. 2013;8(4):e61650.

14. Nur Umami R, Dhenni R, Jajuli A, Nishimura Y, Shimizu H, Utama A. Detection and Identification of Human Enteroviruses among Healthy Children in Antajaya, Bogor, vol. 2; 2009.

15. Apostol LN, Shimizu H, Suzuki A, Umami RN, Jiao MMA, Tandoc A 3rd, Saito M, Lupisan S, Oshitani H. Molecular characterization of enterovirus-A71 in children with acute flaccid paralysis in the Philippines. BMC Infect Dis. 2019; 19(1):370

16. Gaaloul I, Riabi S, Harrath R, Hunter T, Hamda KB, Ghzala AB, Huber S, Aouni M. Coxsackievirus $B$ detection in cases of myocarditis, myopericarditis, pericarditis and dilated cardiomyopathy in hospitalized patients. Mol Med Rep. 2014;10(6):2811-8.

17. Eizirik DL, Op de Beeck A. Coxsackievirus and type 1 diabetes mellitus: the Wolf's footprints. Trends Endocrinol Metab. 2018;29(3):137-9.

18. Arita M, Zhu S, Yoshida H, Yoneyama T, Miyamura T, Shimizu H. A Sabin 3derived poliovirus recombinant contained a sequence homologous with indigenous human enterovirus species $C$ in the viral polymerase coding region. J Virol. 2005:79(20):12650-7.

19. Bingjun T, Yoshida H, Yan W, Lin L, Tsuji T, Shimizu H, Miyamura T. Molecular typing and epidemiology of non-polio enteroviruses isolated from Yunnan Province, the People's Republic of China. J Med Virol. 2008; 80(4):670-9.

20. Apostol LN, Imagawa T, Suzuki A, Masago Y, Lupisan S, Olveda R, Saito M, Omura T, Oshitani H. Genetic diversity and molecular characterization of enteroviruses from sewage-polluted urban and rural rivers in the Philippines. Virus Genes. 2012;45(2):207.

21. Liu W, Wu S, Xiong Y, Li T, Wen Z, Yan M, Qin K, Liu Y, Wu J. Co-circulation and genomic recombination of coxsackievirus A16 and enterovirus 71 during a large outbreak of hand, foot, and mouth disease in Central China. PLoS One. 2014;9(4):e96051.

22. Zhao K, Han X, Wang G, Hu W, Zhang W, Yu XF. Circulating coxsackievirus A16 identified as recombinant type a human enterovirus, China. Emerg Infect Dis. 2011;17(8):1537-40.

23. Wang Y, Zou G, Xia A, Wang X, Cai J, Gao Q, Yuan S, He G, Zhang S, Zeng $M$, et al. Enterovirus 71 infection in children with hand, foot, and mouth disease in Shanghai, China: epidemiology, clinical feature and diagnosis. Virol J. 2015;12:83.

24. Zhao Y, Zhang H, Liu H, Zhang J, He L, Sun H, Huang X, Yang Z, Ma S. Molecular characteristics of hand, foot, and mouth disease for hospitalized pediatric patients in Yunnan, China. Medicine (Baltimore). 2018;97(31): e11610.

25. Simonen-Tikka ML, Hiekka AK, Klemola P, Poussa T, Ludvigsson J, Korpela R, Vaarala O, Roivainen M. Early human enterovirus infections in healthy Swedish children participating in the PRODIA pilot study. J Med Virol. 2012; 84(6):923-30.

26. Attoh J, Obodai E, Adiku T, Odoom JK. Prevalence of human enteroviruses among apparently healthy nursery school children in Accra. Pan Afr Med J. 2014;18:66.

27. Zhang X, Wang H, Ding S, Wang X, Chen X, Wo Y, Wang L, Huang D, Liu W, Cao W. Prevalence of enteroviruses in children with and without hand, foot, and mouth disease in China. BMC Infect Dis. 2013;13:606.

28. Prim N, Rodriguez G, Margall N, Del Cuerpo M, Trallero G, Rabella N. Combining cell lines to optimize isolation of human enterovirus from 
clinical specimens: report of 25 years of experience. J Med Virol. 2013;85(1): $116-20$.

29. Chonmaitree T, Ford C, Sanders C, Lucia HL. Comparison of cell cultures for rapid isolation of enteroviruses. J Clin Microbiol. 1988;26(12):2576-80.

30. Pulli T, Koskimies P, Hyypiä T. Molecular comparison of coxsackie a virus serotypes. Virology. 1995;212(1):30-8.

31. Lipson SM, Walderman R, Costello P, Szabo K. Sensitivity of

rhabdomyosarcoma and Guinea pig embryo cell cultures to field isolates of difficult-to-cultivate group a coxsackieviruses. J Clin Microbiol. 1988;26(7): 1298-303.

32. Oberste MS, Maher K, Kilpatrick DR, Pallansch MA. Molecular evolution of the human enteroviruses: correlation of serotype with VP1 sequence and application to picornavirus classification. J Virol. 1999;73(3):1941-8.

33. Oberste M, Maher K, Kilpatrick D, Flemister M, Brown B, Pallansch M. Typing of human enteroviruses by partial sequencing of VP1. J Clin Microbiol. 1999; 37(5):1288-93.

\section{Publisher's Note}

Springer Nature remains neutral with regard to jurisdictional claims in published maps and institutional affiliations.

Ready to submit your research? Choose BMC and benefit from:

- fast, convenient online submission

- thorough peer review by experienced researchers in your field

- rapid publication on acceptance

- support for research data, including large and complex data types

- gold Open Access which fosters wider collaboration and increased citations

- maximum visibility for your research: over $100 \mathrm{M}$ website views per year

At BMC, research is always in progress.

Learn more biomedcentral.com/submissions 